\title{
Parotid Gland Non-Sebaceous Lymphadenoma: A Case Report
}

\author{
Hiroaki Yamanaka ${ }^{1}$ (D) Hisashi Hasegawa ${ }^{1}$ (D) Makoto Tanaka $^{1}$ (D), Hiroumi Matsuzaki ${ }^{1}$ (D), \\ Takeshi Oshima $^{1}\left(\mathbb{D}\right.$, Masahiko Sugitani $^{2}$ \\ Case Report $>{ }^{1}$ Department of Otolaryngology-Head and Neck Surgery, Nihon University School of Medicine, Tokyo, Japan \\ ${ }^{2}$ Department of Pathology, Nihon University School of Medicine, Tokyo, Japan
}

\begin{abstract}
We here report a rare salivary gland tumor, a non-sebaceous lymphadenoma (NSLA), in the parotid gland with positive technetium-99m $(99 \mathrm{mTc})$ pertechnetate scintigraphy and cervical masses that was difficult to distinguish from malignant lymphoma preoperatively. A 65-year-old Japanese woman presented to our institution with a painless left parotid mass that had been gradually enlarging for three months. Computed tomography and magnetic resonance imaging showed a solid mass $(30 \mathrm{~mm})$ in the tail of the left parotid gland with three swellings (each 10 $\mathrm{mm}$ ) on the periphery of the parotid gland. A low grade malignant lymphoma was diagnosed by fine needle as-
\end{abstract}

ORCID IDs of the authors: H.Y. 0000-0003-0088-7708; H.H. $0000-0002-3111-6300$ M.T. $0000-0003-4414-1131$ H.M. 0000-0003-2710-5454; T.0. 0000-0003-1388-4637; M.S. $0000-0001-8170-2538$

Cite this article as: Yamanaka H, Hasegawa H, Tanaka M, Matsuzaki H, Oshima T, Sugitani M. Parotid Gland Non-Sebaceous Lymphadenoma: A Case Report. Turk Arch Otorhinolaryngol 2019; 57(1): 42-5.

\section{Corresponding Author:}

Hisashi Hasegawa; hasegawa.hisashi@nihon-u.ac.jp

Received Date: 29.01.2019

Accepted Date: 18.02 .2019

Available Online Date: 14.03.2019

C Copyright 2019 by Official Journal of the Turkish Society of Otorhinolaryngology and Head and

Neck Surgery Available online at

www.turkarchotolaryngol.net

DOI: 10.5152/ta0.2019.4129

\section{Introduction}

Non-sebaceous lymphadenoma (NSLA), a rare benign salivary gland tumor, is included in the World Health Organization's classification of 2005 (1). These tumors are a type of lymphadenoma with intermingled lymphoid and epithelial components that lack sebaceous differentiation. Only 47 cases have been reported in English literature (2-6). NSLA most commonly arises within the parotid gland (39 cases, 83\%), with rare reports of origination in the minor salivary glands of the lips or submandibular glands. It characteristically grows slowly over many years. Recurrence, malignant transformation, and metastasis to multiple organs have not been reported. It is difficult for clinicians or pathologists to make the diagnosis preoperatively. Moreover, most published reports have focused on the pathological characteristics. Thus, otorhinolaryngologists may not be familiar with its clinical features.

We here report an NSLA of the parotid gland with positive technetium-99m $(99 \mathrm{mTc})$ pertechnetate piration cytology. Gallium-67 scintigraphy showed mild positivity. On $99 \mathrm{mTc}$ pertechnetate scintigraphy, the mild accumulation remained after oral stimulation with a mixture of ascorbic acid and calcium pantothenate. The patient underwent superficial parotidectomy with removal of the cervical masses. Our findings in this patient suggest that $99 \mathrm{mTc}$ positivity may constitute a clue to the preoperative diagnosis of NSLA that has pathologically overlapping sites with Warthin tumor.

Keywords: Non-sebaceous lymphadenoma, parotid gland, cervical lymphadenopathy, technetium-99m pertechnetate scintigraphy, neoplasia scintigraphy and cervical masses that was difficult to distinguish from malignant lymphoma preoperatively. To the best of our knowledge, this is the first report of NSLA examined by $99 \mathrm{mTc}$ pertechnetate scintigraphy and with cervical lymphadenopathy.

\section{Case Presentation}

A 65-year-old Japanese woman was referred to our clinic with a painless left parotid mass that had been growing slowly for three months. She had had primary biliary cholangitis for eight years and sometimes had mild liver dysfunction. She had not lost weight or had night sweats in the previous few months. Physical examination revealed a $30 \times 20 \mathrm{~mm}$ mobile mass of elastic to hard consistency inferior to the left ear. There was no significant cervical, axillary, or inguinal lymphadenopathy, and no facial nerve dysfunction. As to blood tests, her liver function was normal, and sIL-2R was negative. Computed tomography (CT) of the head and neck showed a well-demarcated enhancing solid mass $(35 \times 34 \times 13 \mathrm{~mm})$ in the tail of the left parotid gland 
(Figure 1). Magnetic resonance imaging (MRI) of the head and neck revealed a well-defined, gadolinium-enhancing solid mass with hypointensity on T1-weighted and hyperintensity on T2weighted images (Figure 2). There was no invasion of the surrounding tissues and the three nodules were identified around the parotid gland. Fine needle aspiration cytology (FNAC) revealed many small to medium lymphocytes, a few large lymphocytes with mild nuclear atypia and increased chromatin and a few tingible body macrophages. The lesion was Class III according to the Papanicolaou classification. It was difficult to distinguish between inflammatory changes and low grade lymphoma on FNAC.

To further determine the diagnosis, two scintigraphic examinations were performed. On gallium-67 (Ga67) scintigraphy, there was mild accumulation in the lesion in the left parotid gland. On $99 \mathrm{mTc}$ pertechnetate scintigraphy, there was accumulation

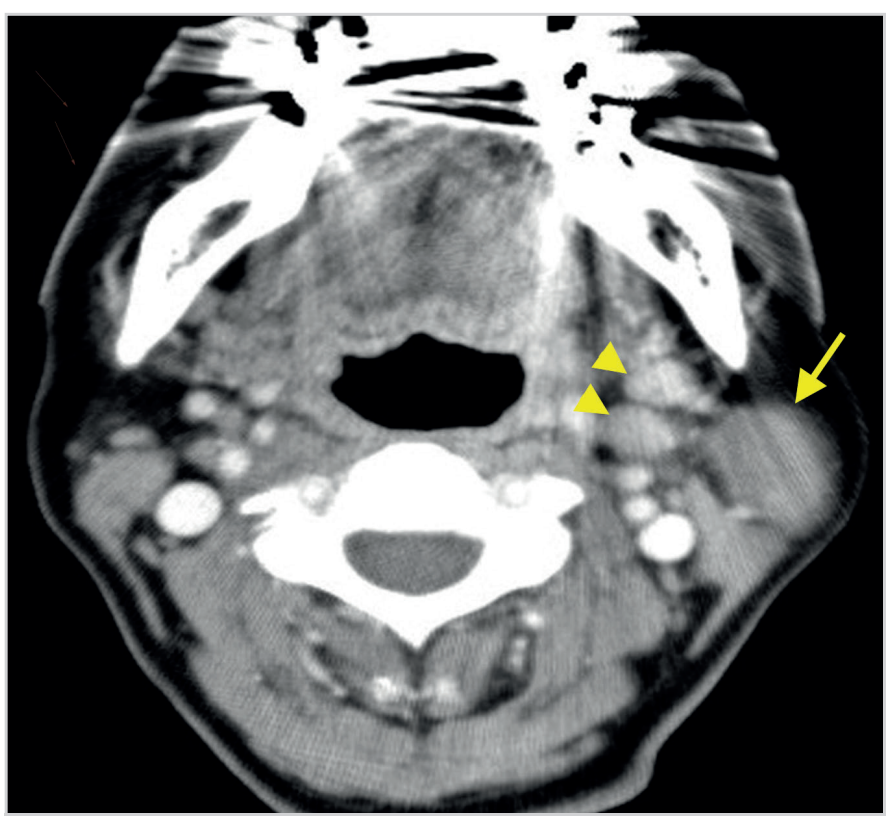

Figure 1. Computed-tomography of the head and neck. Axial section showed a well-demarcated enhancing solid mass (arrow) in the tail of the left parotid gland with nodules (arrowheads) in the periphery of the parotid gland in either parotid and submandibular glands. Mild accumulation remained in the left parotid gland after oral stimulation with a mixture of ascorbic acid and calcium pantothenate (Figure 3). Thus, a benign parotid gland tumor such as Warthin tumor or pleomorphic adenoma was suspected preoperatively. However, the presence of cervical nodules adjacent to the left parotid gland meant that malignant lymphoma could not be excluded.

The patient underwent superficial parotidectomy with removal of the cervical masses to establish a definite diagnosis and as treatment. None of the cervical masses were adherent to the surrounding tissues. A partial parotidectomy was performed, the operative specimen being $4.5 \times 3.5 \times 1.0 \mathrm{~cm}$. Microscopically, the tumor was encapsulated by fibrous tissue with clear borders between it and the unaffected salivary gland. Tubuloglandular structures and many lymphocytes, some of which were forming reactive lymph follicles with germinal centers, were observed in the tumor (Figure 4). The epithelial and lymphoid components were not carcinomatous or lymphomatous, respectively. No metastases were found in the excised lymph nodes. The final pathological diagnosis was

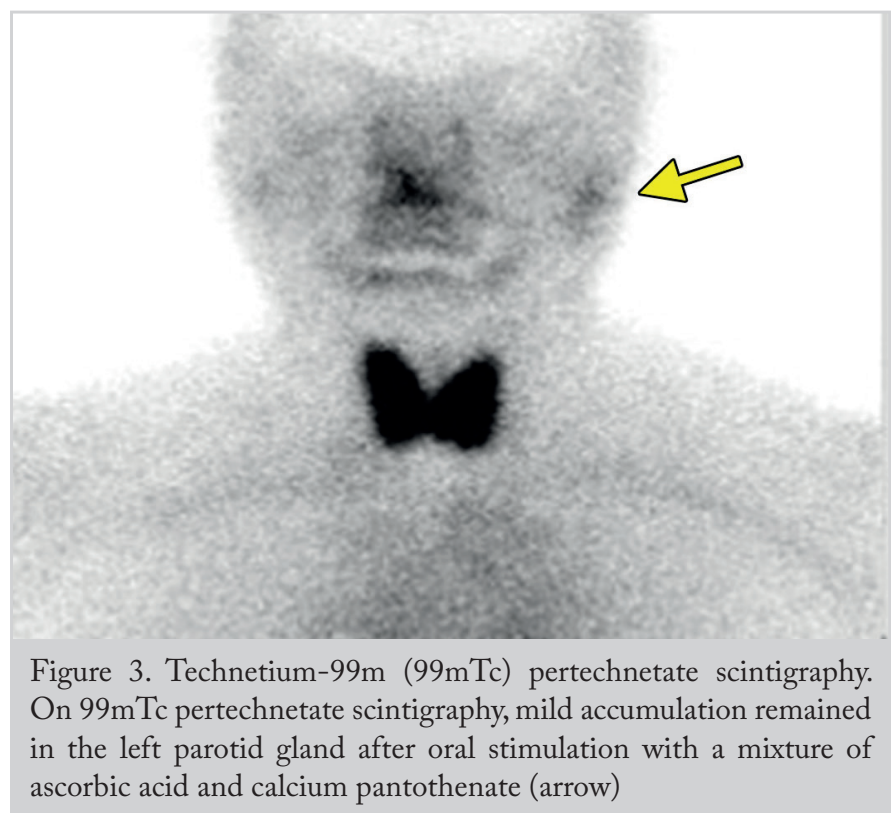

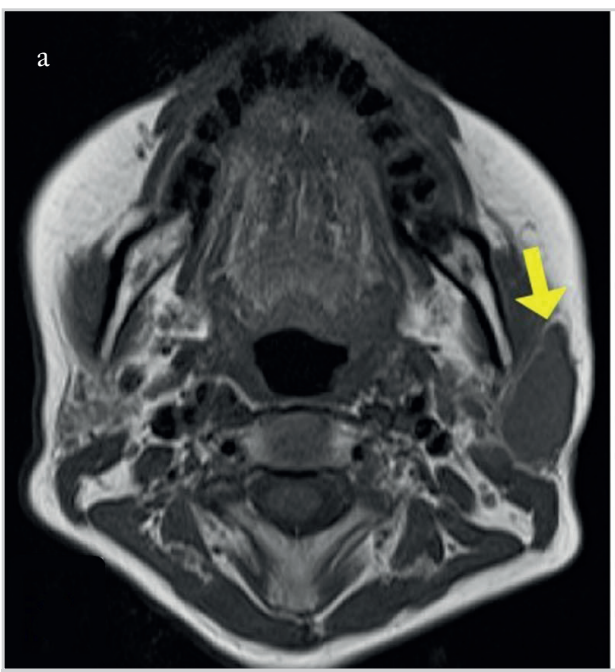
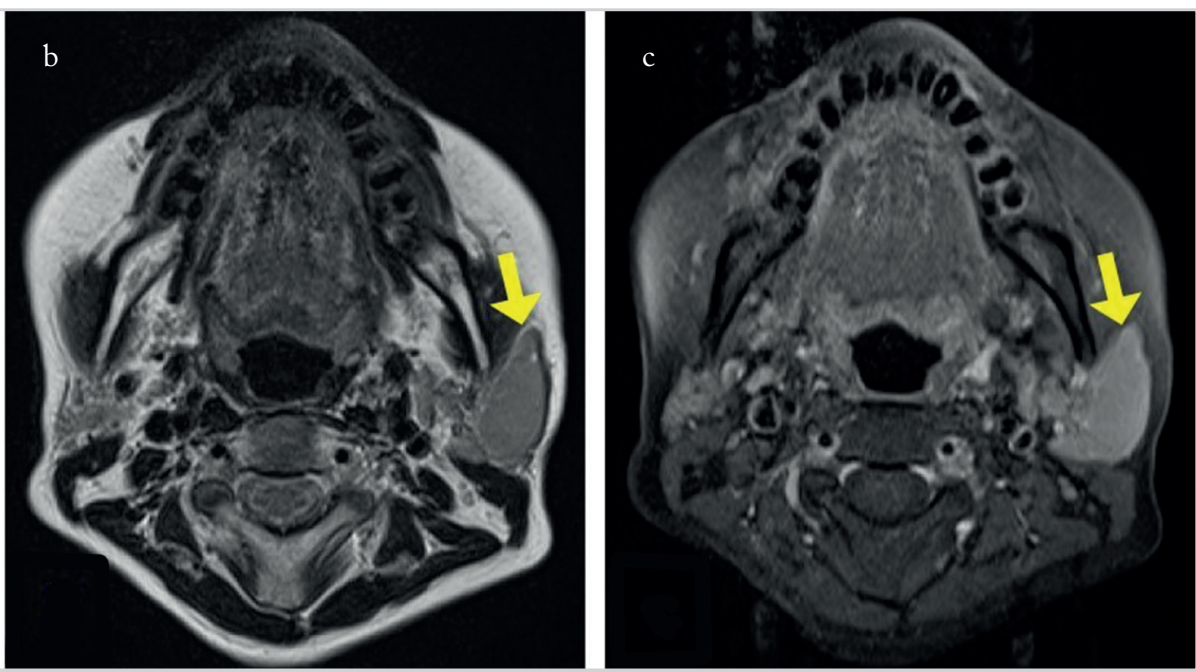

Figure 2. a-c. Magnetic resonance imaging of the head and neck 

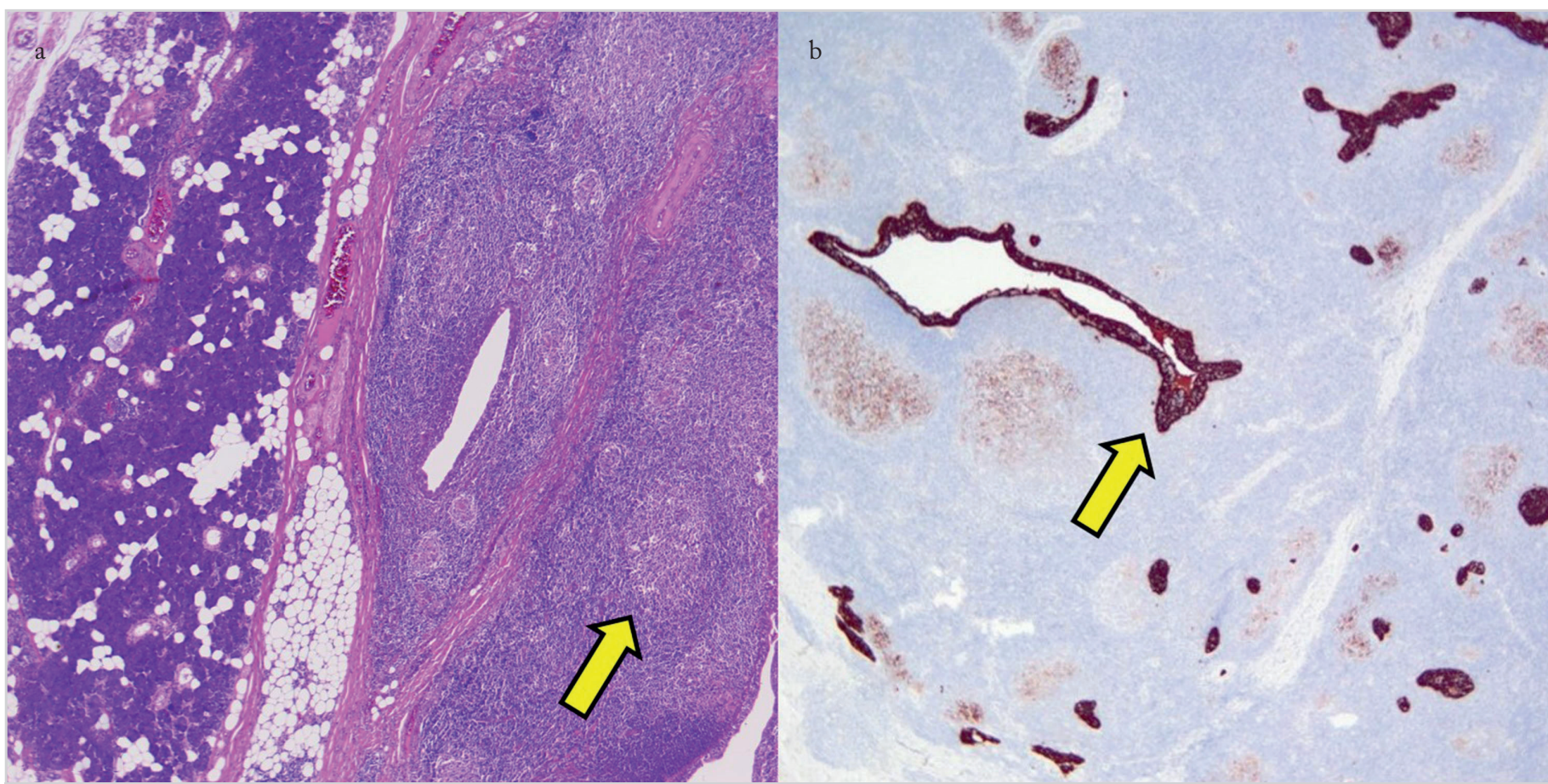

Figure 4. a, b. Hematoxylin and eosin and immunohistochemical staining with AE1/AE3 in the parotid tissue. Non-sebaceous lymphadenoma (right) and normal parotid gland (left) are shown. The tumor was composed of lymphatic tissue with lymphatic follicles. No sebaceous glands were identified. (Hematoxylin and eosin staining, X40) (a); Many epithelial cell islands of varying size are present. (AE1/AE3 staining, X40) (b)

lymphadenoma, non-sebaceous type. The patient had no adverse events and was discharged in a stable condition. No recurrence was detected during 54 months of follow-up. Informed consent for publication was obtained from the patient.

\section{Discussion}

We here present a case of a rare lesion, NSLA, that originated in the parotid gland, was positive on $99 \mathrm{mTc}$ pertechnetate scintigraphy, and was associated with surrounding reactive lymph nodes. To the best of our knowledge, these lesions have never been diagnosed as NSLA preoperatively by FNAC. Thus, our finding of $99 \mathrm{mTc}$ pertechnetate scintigraphy positivity after oral stimulation is expected to help clinicians to diagnose NSLA preoperatively and to distinguish NSLA from other parotid gland tumors.

It is very difficult for otolaryngologists or pathologists to diagnose NSLA preoperatively. A definite preoperative diagnosis based on FNAC findings has never been reported (2-6). It may be impossible to diagnose a NSLA without examining the whole tumor.

The finding that $99 \mathrm{mTc}$ scintigraphy after oral stimulation was weakly positive in this case is interesting. No other articles has described the relationship between NSLA and $99 \mathrm{mTc}$ scintigraphy. $99 \mathrm{mTc}$ scintigraphy positivity in the parotid gland suggests a tumor, specifically Warthin tumor because it does not communicate with the salivary ductal system, the accumulated $99 \mathrm{mTc}$ scintigraphy remains in the gland without being secreted. The reason that this case presented $99 \mathrm{mTc}$ pertechnetate positive could be that lymphadenoma and Warthin tumor have pathologically overlapping sites (7). 99mTc scintigraphy may aid in preoperative diagnosis of NSLA and should be performed in future cases.

We present a rare case of NSLA in the parotid gland with surrounding lymphadenopathy. This combination is rare. The pathology responsible for the lymphadenopathy is uncertain, the most likely possibility being a nonspecific reaction to the parotid gland tumor, this being consistent with the location of the lymphadenopathy and its pathological features. However, cervical lymphadenopathy with a benign parotid gland tumor is unusual. The NSLA may have stimulated the chronic inflammation associated with our patient's primary biliary cholangitis (8). Future reports of this rare combination are needed.

\section{Conclusion}

We present a rare case of NSLA in the parotid gland with positive $99 \mathrm{mTc}$ pertechnetate scintigraphy and cervical lymphadenopathy. We consider that $99 \mathrm{mTc}$ pertechnetate positivity may be useful for making a preoperative diagnosis of NSLA.

Informed Consent: Written informed consent was obtained from the patient who participated in this study.

Peer-review: Externally peer-reviewed.

Author Contributions: Concept - H.Y., H.H., M.T.; Design - H.Y., H.H., M.T.; Supervision - H.M., T.O., M.S.; Resource - H.Y., H.H., H.M.; Materials - H.Y., H.H., M.T.; Data Collection and/or Processing - H.Y., H.H., M.T.; Analysis and/or Interpretation - H.Y., H.H., M.S.; Literature Search - H.Y., H.H., M.T.; Writing - H.Y., H.H., M.S.; Critical Reviews - H.M., T.O., M.S. 
Acknowledgements: The authors thank Dr. Trish Reynolds, MBBS, FRACP, from Edanz Group for editing a draft of this manuscript.

Conflict of Interest: The authors have no conflicts of interest to declare.

Financial Disclosure: The authors declared that this study has received no financial support.

\section{References}

1. Barnes L, Eveson JW, Reichart P, Sidransky D. Pathology and genetics of head and neck tumours. Lyon: IARC; 2005.p. 269.

2. Liu G, He J, Zhang C, Fu S, He Y. Lymphadenoma of the salivary gland: Report of 10 cases. Oncol Lett 2014; 7: 1097-101. [CrossRef]

3. Ishii A, Kawano H, Tanaka S, Yamamoto Y, Nakamoto T, Hirose $\mathrm{Y}$, et al. Non-sebaceous lymphadenoma of the salivary gland with serous acinic cell differentiation, a first case report in the literature. Pathol Int 2013; 63: 272-6. [CrossRef]
4. Mori D, Akashi M, Shibaki M, Koike E, Miyazaki J. Nonsebaceous lymphadenoma in the parotid gland: true neoplastic or reactive? A report of two cases. Int J Surg Pathol 2013; 21: 509-13. [CrossRef]

5. Angiero F, Ferri A, MariaValente G, Cattoretti G. Nonsebaceous lymphadenoma of salivary gland: report of a case with immunohistochemistry and review of the literature. Oral Surg Oral Med Oral Pathol Oral Radiol 2012; 114: e41-e7. [CrossRef]

6. Auclair PL. Tumor-associated lymphoid proliferation in the parotid gland: a potential diagnostic pitfall. Oral Surg Oral Med Oral Pathol 1994; 77: 19-26. [CrossRef]

7. Kwon GY, Kim EJ, Go JH. Lymphadenoma arising in the parotid gland: a case report. Yonsei Med J 2002; 43: 536-8. [CrossRef]

8. Hiramatsu S, Nebiki H, Ueno A, Maruyama H, Suekane T, Yamasaki $\mathrm{T}$, et al. [A case of primary biliary cirrhosis with systemic lymph node enlargement]. Nihon Shokakibyo Gakkai Zasshi 2012; 109: 1784-90. 